\title{
NUMERICAL INVESTIGATION OF HEAT TRANSFER AND FLOW CHARACTERISTICS IN SHELL-AND U-TUBE HEAT EXCHANGER WITH BAFFLES
}

\author{
Prof Sadoun Fahad ${ }^{*}$, Assist Prof Ahmed Kadhim Alshara ${ }^{* *}$ and Eng. Murtatha Saeed ${ }^{* * *}$ \\ ${ }^{*} \&$ ** Technical Engg college Basrah- Southern Technical University-Iraq \\ **** Engineering college Misan- University of Misan-Iraq
}

\begin{abstract}
In this paper the numerical model of cylindrical coordinates, three dimensional of a laminar heat transfer and fluid flow inside shell and tube heat exchanger is examined. The thermo-hydraulic performance of heat exchangers is predicted with finite volume method by CFD simulations using ANSYS 15.0 code. Shell-and-tube heat exchanger is consisted of one pass of warm water laminar flow at the shell side and two passes single tube of laminar cold water. The annular baffles are inserted on shell side, and on the facing distances of the length of tube from the outer surface. Baffles are inserted with staggered position on the shell and tube to achieve good fluid circulation. Also baffles on the tube side are varied with angle inclination, number and diameter while only number and length on the shell side. The tube baffles angle inclination as $\left(45^{\circ}, 0^{\circ}\right.$ and $\left.-45^{\circ}\right)$ and without baffles and the range of Reynolds number from 100 to 2000. The results show high effect of baffles angles on the heat exchanger performance at high Reynolds number. Maximum heat transfer from hot fluid occurs at baffle with angle $0^{\circ}$ and high $30 \mathrm{~mm}$. Also baffles number increases Nusselt number at high fluid flow rate while a little effect of baffle height and number on the fluid pressure drop is absorbed as obtained by Mica et.al [1].
\end{abstract}

KEYWORDS: Shell-and-tube; Numerical simulation; baffle inclination angle.

\section{INTRODUCTION}

The heat exchange between fluids in engineering applications is one of the important processes. It is classified depending upon their process fluids, application, and mode of flow and heat transfer. One type of heat exchangers called tubular or shell and tube which are widely used. Shell-and-tube heat exchangers are used extensively in chemical engineering, petroleum refining, and power generation, among others. Vukic. et al [2] investigated local heat transfer and pressure drop on the shell side of shell-andtube heat exchangers with segmental baffles for different baffle spacing. They found for same Reynolds number, the pressure drop and average heat transfer increase by increasing baffle spacing due to a reduced leakage through the baffle-shell clearance. Vukic. et al $[3,4]$ carried out experimental and numerical heat and flow in shell and tube heat exchanger to show effect of number of segmental baffles, baffle cut size, baffle distance, the first and the last baffle position to inlet and outlet nozzle, size of the constructive on effectiveness of the shell and tube heat exchanger. They used heat exchanger with one pass shell and two pass 24 tubes (U-tube) in shell. Three packages of segmental baffle cuts of 22,27 and
$32 \%$ are located in the shell. There are 5 segmental baffles in every package. The results showed the heat exchange depending on the geometry of shell side. Abdur Rahim et al. [5] studied the effects of baffle inclination angle on flow and heat transfer of a heat exchanger with segmental baffles, three inclination angles of baffle $0^{\circ}, 10^{\circ}$ and $20^{\circ}$. These results concluded for the tubular heat exchanger that $20^{\circ}$ baffle inclination angle hold a best performance comparing to $10^{\circ}$ and $0^{\circ}$ inclinations. Amirtharaj et al. [6] studied heat and flow in shell and tube heat exchanger with various design styles of baffle. They used CFD analysis for two models of shell and tube heat exchanger, the first with segmental baffles and second with inclined baffles. The Kern method was used to do the mathematical calculation. Results showed high effect of the performance of heat transfer for heat exchanger (shell and tube) with inclined baffles. Thundil et al. [7] carried out the effects of different baffle inclination angles on the heat transfer and fluid flow characteristics of a heat exchanger (shell and tube) for three inclination angles of baffle namely $0^{\circ}, 10^{\circ}$, and $20^{\circ}$. They compared the performance of two tubular heat exchangers, the first with segmental baffles inclined on the direction of fluid flow and the 
second with perpendicular on the direction of fluid flow. The results concluded that baffle inclination angle $20^{\circ}$ of tubular heat exchanger gives better performance compared to $10^{\circ}$ and $0^{\circ}$ inclination angles. Lei et al. [8] investigated the flow and heat transfer in a heat exchanger with the effect of the inclination angle of helical baffle. They found in the all cases, the pressure drop decreases with increasing of baffle inclination angle. Also, when consume the same pumping power; the heat exchangers will have a higher heat transfer coefficient with helical baffles. The performance enhancement increases when the baffle inclination angle $\alpha<45^{\circ}$, and decreases at $\alpha>45^{\circ}$. Vyas [9] concluded that heat transfer between fluids in shell and tube heat exchanger is highly influenced with baffle spacing, baffle cut size, number of baffles and size of inlet and outlet zones.

From this review, it is clear that increasingly need to investigate the enhancement of heat transfer in the single U-tube heat exchanger with inserted annulus baffles. Therefore, the aims of this work is to investigate the laminar flow and heat transfer characteristics in the single U-tube heat exchanger with inserted annulus baffles with different the angles, number and diameter of baffles.

\section{THEORETICAL ANALYSES}

\subsection{Physical model}

The present physical model is shown in the Fig.1, which represents the one shell pass and two passes of a single tube in the form called U-tube heat exchanger. The working fluid is water for both sides, the hot fluid run in the shell and cold fluid flow through the tube, the tube wall separating between for them. The inner and outer diameter of the tube is $0.0169 \mathrm{~m}, 0.01905 \mathrm{~m}$ respectively, and the length of the U-tube is $2.1 \mathrm{~m}$. The shell diameter is $0.188 \mathrm{~m}$, and the length of the shell is 1.05 . The annular baffles are used on shell side and on the outer surface of the tube, and material of tube heat exchange and baffles is copper, while shell material is plastic type (PVC). The geometric model is simulated by varying the number baffle, diameter baffle and tube baffle angle i.e., $+45^{\circ}, 0^{\circ}$ and $-45^{\circ}$, as shown in Fig.2.

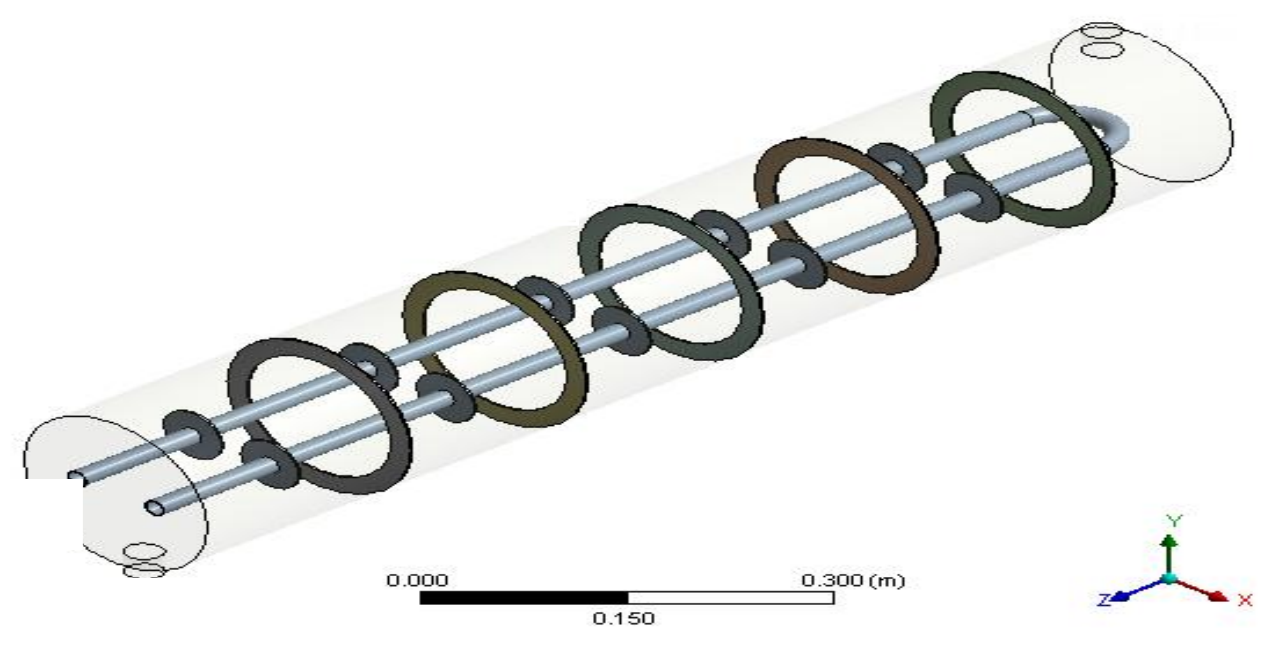

Fig. (1): Isometric view of arrangement of baffles and tubes of shell and tube heat exchanger with baffle angle $(\alpha)$ $0^{\circ}, \mathrm{NB} 5, \mathrm{Bh}=20 \mathrm{~mm}$. 


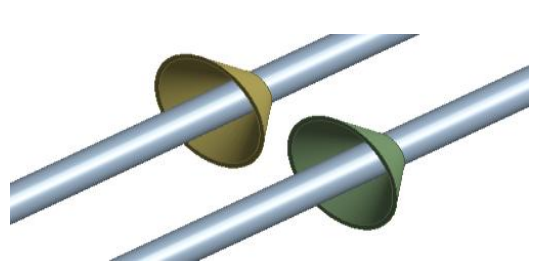

a
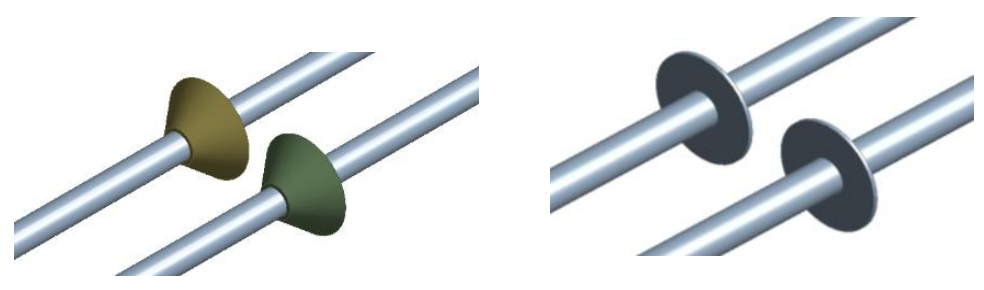

Fig.(2): The model of the tube baffle angle in degree, $\mathrm{Bh}=20 \mathrm{~mm} ;$ (a) $-45^{\circ}$;(b) $+45^{\circ}$; (c) $0^{\circ}$.

To simplify the numerical simulation the following assumptions are considered:

- 3D, laminar steady state flow.

- Incompressible fluids with single phase.

- Negligible viscous dissipation, radiation and natural convection.

- The shell surface is adiabatic

- The thermal properties of fluid are independent on temperature.

\subsection{Governing equations}

The system of equations which are governed the present model as: continuity, momentum and energy equations and are satisfied the simulation conditions of this case. Since the present model is assumed to be laminar and steady, three dimensional cylindrical coordinates as the following:

Heat transfer is a conjugate process, combining heat conduction in the solid wall and convection in the working fluids and the governing equations are written as [10], [11]:

(i) Continuity equation:

$\frac{\partial u_{r}}{\partial r}+\frac{u_{r}}{r}+\frac{1}{r} \frac{\partial u_{\theta}}{\partial \theta}+\frac{\partial u_{z}}{\partial z}=0$

(ii) Momentum equation:

\section{$\theta$-direction}

$\rho\left(u_{r} \frac{\partial u_{\theta}}{\partial r}+\frac{u_{\theta}}{r} \frac{\partial u_{\theta}}{\partial \theta}+\frac{u_{r} u_{\theta}}{r}+u_{z} \frac{\partial u_{\theta}}{\partial z}\right)=-\frac{1}{r} \frac{\partial P}{\partial \theta}+\mu\left(\frac{\partial^{2} u_{\theta}}{\partial r^{2}}+\frac{1}{r} \frac{\partial u_{\theta}}{\partial r}-\frac{u_{\theta}}{r^{2}}+\right.$

$\left.+\frac{1}{r^{2}} \frac{\partial^{2} u_{\theta}}{\partial \theta^{2}}+\frac{2}{r^{2}} \frac{\partial u_{r}}{\partial \theta}+\frac{\partial^{2} u_{\theta}}{\partial z^{2}}\right)$

\section{r-direction}

$\rho\left(u_{r} \frac{\partial u_{r}}{\partial r}+\frac{u_{\theta}}{r} \frac{\partial u_{r}}{\partial \theta}-\frac{u_{\theta}^{2} \theta}{r}+u_{z} \frac{\partial u_{r}}{\partial z}\right)=-\frac{\partial P}{\partial r}+\mu\left(\frac{\partial^{2} u_{r}}{\partial r^{2}}+\frac{1}{r} \frac{\partial u_{r}}{\partial r}-\frac{u_{r}}{r^{2}}+\frac{1}{r^{2}} \frac{\partial^{2} u_{r}}{\partial \theta^{2}}-\right.$

$\left.\frac{2}{r^{2}} \frac{\partial u_{\theta}}{\partial \theta}+\frac{\partial^{2} u_{r}}{\partial z^{2}}\right)$

\section{z-direction}

$\rho\left(u_{r} \frac{\partial u_{z}}{\partial r}+\frac{u_{\theta}}{r} \frac{\partial u_{z}}{\partial \theta}+u_{z} \frac{\partial u_{z}}{\partial z}\right)=-\frac{\partial P}{\partial z}+\mu\left(\frac{\partial^{2} u_{z}}{\partial r^{2}}+\frac{1}{r} \frac{\partial u_{z}}{\partial r}+\frac{1}{r^{2}} \frac{\partial^{2} u_{z}}{\partial \theta^{2}}+\frac{\partial^{2} u_{z}}{\partial z^{2}}\right)$

(iii) Energy equation

- For fluid region:

$\rho C p\left(u_{r} \frac{\partial T}{\partial r}+\frac{u_{\theta}}{r} \frac{\partial T}{\partial \theta}+u_{z} \frac{\partial T}{\partial z}\right)=k\left(\frac{\partial^{2} T}{\partial r^{2}}+\frac{1}{r} \frac{\partial T}{\partial r}+\frac{1}{r^{2}} \frac{\partial^{2} T}{\partial \theta^{2}}+\frac{\partial^{2} T}{\partial z^{2}}\right)$ 


\section{- For solid region:}

$$
\frac{\partial^{2} T s}{\partial r^{2}}+\frac{1}{r} \frac{\partial T s}{\partial r}+\frac{1}{r^{2}} \frac{\partial^{2} T s}{\partial \theta^{2}}+\frac{\partial^{2} T s}{\partial z^{2}}=0
$$

\subsection{Boundary conditions}

The Partial differential equations are solved with following boundary conditions;

*The shell inlet temperature is set to $\mathrm{T}_{\mathrm{h}}=360 \mathrm{~K}$ and tube inlet temperature $\mathrm{T}_{\mathrm{c}}=300 \mathrm{~K}$, and constant inlet fluid velocity $\mathrm{U}_{\text {in }}$.

*The outlet shell and tube is assigned zero pressure.

*No slip condition is applied to all of the solid surfaces.

*The shell wall set as adiabatic.

* Wall tube and baffle are continuous boundary condition (interfaces).

$$
\operatorname{Re}=\frac{\rho u_{i} D_{h}}{\mu}
$$

The Nusselt number $(\mathrm{Nu})$;

$$
\mathrm{Nu}=\frac{\mathrm{h} \mathrm{D}}{\mathrm{\kappa}}
$$

and the friction factor $(f)$

$$
f=\frac{\Delta \mathrm{P}}{\left(\rho u^{2} / 2\right)(L / D)}
$$

\subsection{Grid systems}

The geometrical modeling and grid generation procedure are carried out with commercial CFD preprocessor ANSYS 15.1, grid generation is performed using meshing [ANSYS ICEM CFD]. In the most flow region the models are discretized with tetrahedral meshes for shell and with hexahedral meshes for the U-tube and baffle region. The grid distribution of the physical model is presented in Fig.3. The one of the most important tests of numerical analysis of a problem which should be done is grid independence test. The grid independence test was completed for this

\subsection{Numerical method}

The commercial software is Fluent ANSYS 15.0 chosen as the CFD tool for the present work. The finite volume method is used and second order upwind is applied for Navier-Stokes equations. The scheme that used for pressure computation is the standard difference and SIMPLE algorithm is adopted for the coupling pressure and velocity field. The residuals for the flow variables are $10^{-6}$ for momentum and $10^{-8}$ for energy in each control volume [4].

The following parameters are used; The Reynolds number $(\mathrm{Re})$

model in numerical problem. These results depend on the number of grids generated which shown in Fig.4. The number of grids without change in results were selected as best grid size and the results become independent of grids (the number of nodes $=453467$ and number of elements=1942789). In Fig. 4, the temperature of hot fluid at the outlet is considered for check the grid independence. 


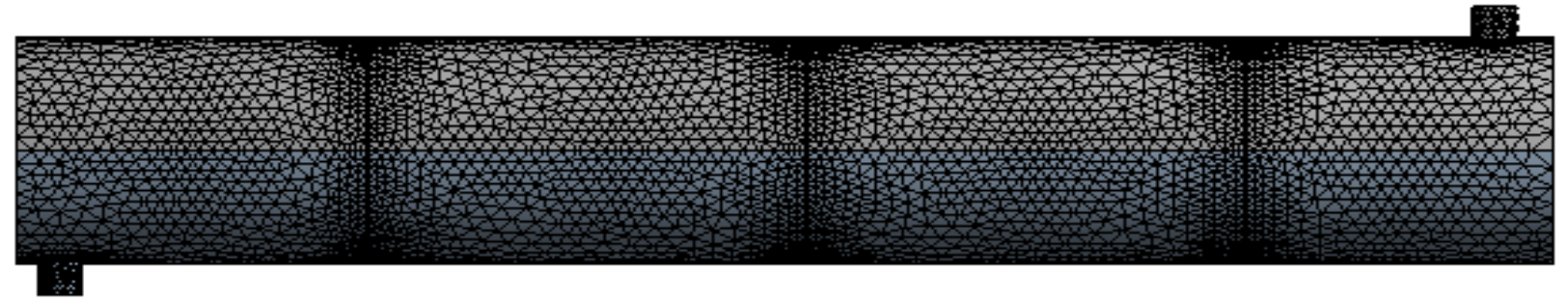

(a) Overall meshes of heat exchanger

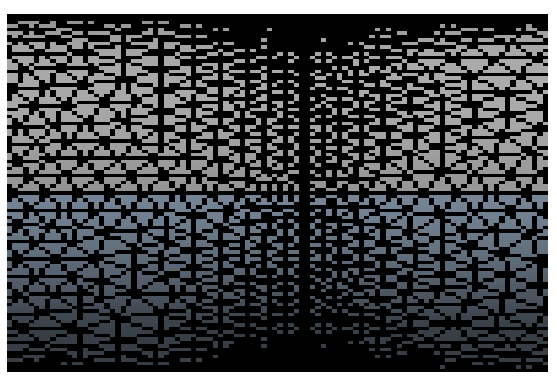

(b) Partial meshes of shell

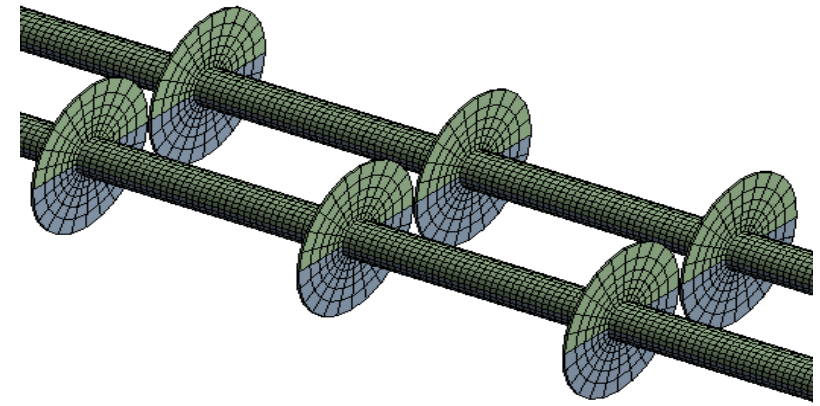

(c) Partial meshes of tube baffle $\left(0^{\circ}\right)$

Fig. (3): Meshes of computational model.

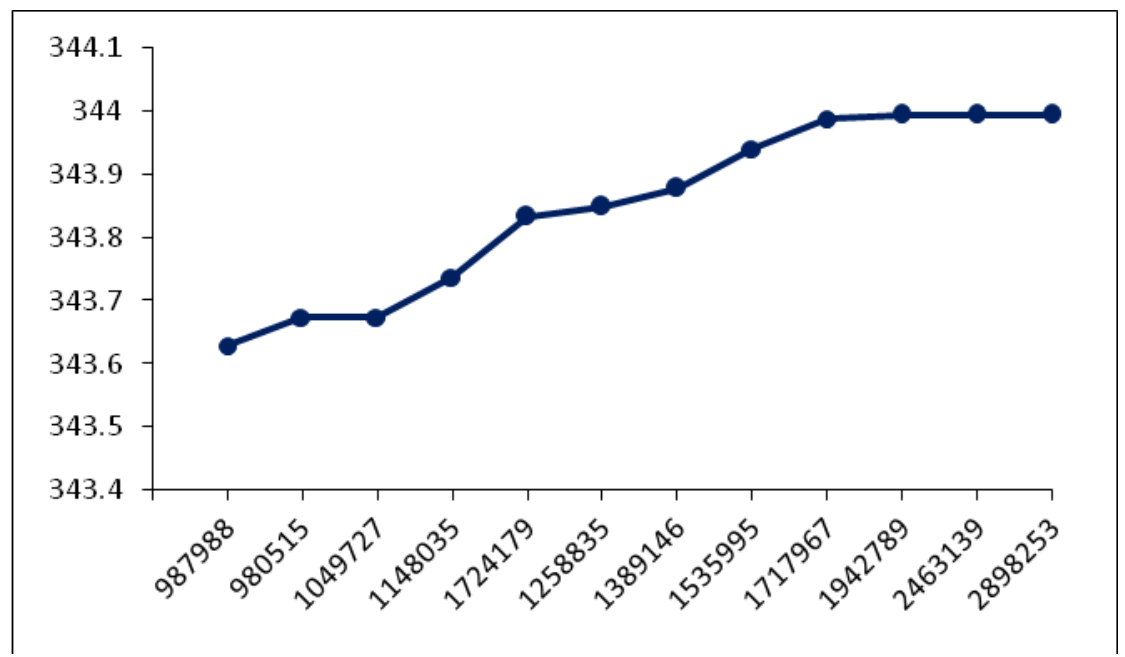

Fig.(4): Grid independence test based on the outlet of hot fluid temperature.

\subsection{Validation of numerical model}

In order to validate the numerical model the friction factor $(f)$ is carried out in the tube side. The pressure loss in a tube can be generally described in terms of Darcy's friction factor. To validate the numerical solutions accuracy, the friction factor of the present CFD results is compared with the Darcy fraction factor [10]. From Fig. 5 it is found that the maximum error of the friction factor between present results and theoretical data results are about $8.82 \%$. 


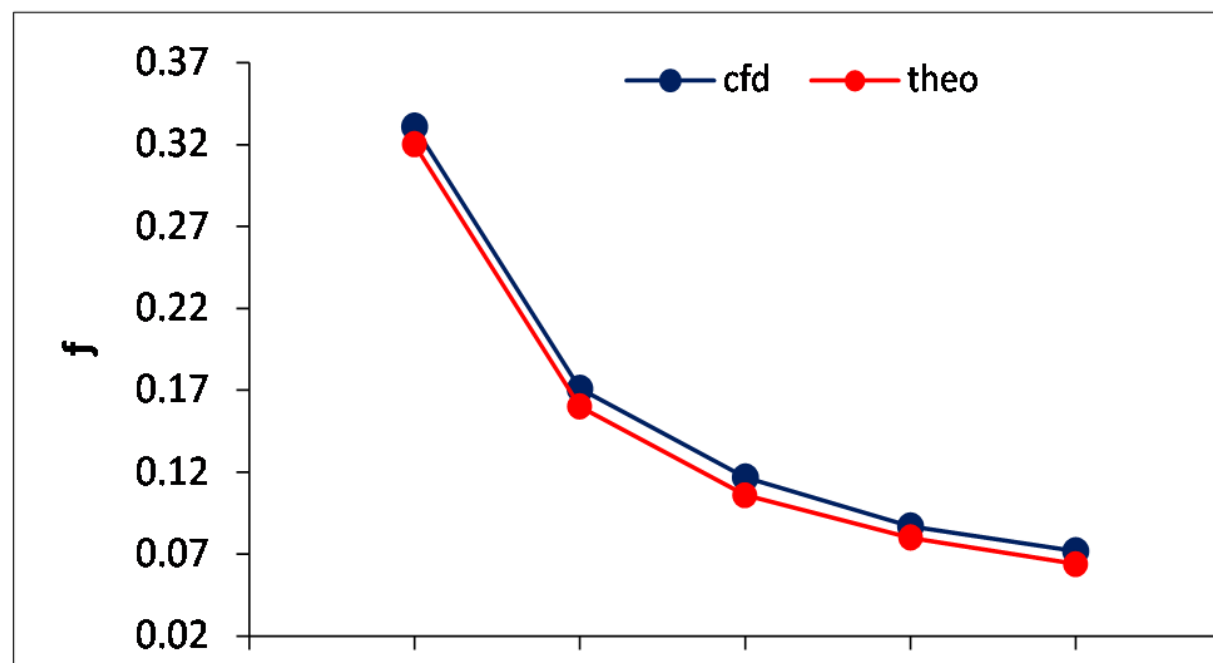

Fig. (5): Comparison of the present results with the theoretical friction factor $(f)$ [10] of the plain tube.

\section{RESULTS AND DISCUSSIONS}

In the present work the effect of various parameters on the characteristics and performance of heat exchanger shell and U-tube will be studied at laminar flow. Table.2 shows the important parameters which are used in this study to test the best parameters that the performance of the heat exchanger is depended on them.

Table. (2): Variables and range of values

\begin{tabular}{ccc}
\hline Parameters & Symbol & Range of Values \\
\hline Angle of baffle & $\mathrm{A}$ & Without baffle $,+45^{\circ}, 0^{\circ},-45^{\circ}$ \\
\hline Number of baffle & $\mathrm{Nb}$ & $3,5,8$ \\
\hline Baffle height & $\mathrm{Bh}(\mathrm{mm})$ & $10,20,30$ \\
\hline Reynolds number of shell & $\mathrm{Re}$ & $100,500,1000,1500,2000$ \\
\hline Reynolds number of tube & $\mathrm{Re}_{\mathrm{t}}$ & 600 \\
\hline
\end{tabular}

\subsection{Hydrodynamic Performance.}

Fig.6 shows the variation of pressure drop of shell side with Reynolds number of shell for various baffle inclination angles $\left(+45^{\circ}, 0^{\circ},-45^{\circ}\right)$. It is clear that the pressure drop of shell increases with increasing mass flow rate of shell-side and its increase is more clear in high mass flow rate range. It can be noted that the effect inclination angle of baffle on the pressure drop is relatively small. The pressure drop increases with the increase of baffle inclination angle at positive direction and decrease at negative direction. For the Reynolds number of shell 2000, the pressure drop increases $(12.18 \%, 16.17 \%$ and $7.03 \%)$ when baffle inclination angle varying $\left(+45^{\circ}, 0^{\circ},-45^{\circ}\right)$ respectively, comparing with case without baffles. It is understood that the increase of pressure drop is more effective in higher Reynolds number region for all inclination angles.
Also be seen from Fig.7 and Fig.8 the variation of pressure drop of shell side with shell Reynolds number for different number and height of baffles. In the fact, the baffles work as guide and obstacles for the flow, which leads to increase the pressure drop. In a heat exchanger without baffles the general flow direction would be flow from the inlet to the outlet and the only contributions to the pressure drop would come from crossing the tube and the friction along the shell wall. Adding baffles disables the flow to go in this direction and therefore pressure drop is increased.

It is seen from the figure that, the shell-side pressure drop increases at the number and height baffle increases. This behavior is a result of increasing the flow circulation of fluid around tube downstream of the baffles then increase the velocity of flow. 


\subsection{Thermal Performance}

Fig.9 shows the varying of average Nussult number of shell side with shell Reynolds number at different inclination angles baffle. From this figure it is clear that, the average Nussult number increases when shell Reynolds number increases for all baffle angles. The Nusselt number with baffles is higher than that without baffles tube, because the presence of circular baffles causes the disturbance and random movement of the flow field which leads to higher heat transfer rate. Also, it limits the growth of boundary layer of fluid close to the heat transfer surface and leads to periodic disruption of the layer due to change in the direction of flow. The Nusselt number for $\alpha>$ $0^{\circ}$ is higher than those of other tubes for $\alpha<0^{\circ}$. Whereas the Nusselt number of the shell side when $\alpha=0^{\circ}$ is the highest. However, the baffle number and baffle height hence the heat transfer coefficient due to increase the turbulence with increasing the baffle number and baffle height as show in Fig.10 and Fig.11.

It can also be seen that the heat exchanger with $0^{\circ}$ baffle inclination angle obtained at a reasonable pressure gradient with maximum tube outlet temperature. Furthermore, it can be concluded that $0^{\circ}$ baffle inclination angle gives a best performance compared to $+45^{\circ}$ and $-45^{\circ}$ inclination angles. The magnitudes of the heat transfer rate and the pressure drop at $0^{\circ}(\mathrm{Re}=2000)$ are 1061.452W and 25.343 Pa respectively.

Fig.12, shows the variation of effectiveness with Reynolds number for different inclination of angle baffle at $\mathrm{Nb}=5, \mathrm{Bh}=20$. It can be seen that indicates that the effectiveness of $0^{\circ}$ is optimum angle baffle. This may be attributed to resistance that obtained from the right angle $\left(0^{\circ}\right)$ which gives more time for heat exchanger between solid and hot fluid.

Fig.13 illustrates the variation of heat exchanger effectiveness versus shell Reynolds number for different baffle numbers. As seen in this figure, the effectiveness increases with increasing shell Reynolds number for all cases, because the increase in shell Reynolds number means a higher velocity which leads to enhance the heat transfer rate between the two fluids.

Fig .(14) presents the streamline of fluid flow. The results show the effect of baffles on the hot fluid flow. There is guidance for fluid flow by baffle which helps in a forced movement around the tube and thus increases heat transfer between fluids. So the high velocity reach to $0.04 \mathrm{~m} / \mathrm{s}$ near the tube compared to surface far away from the tube.

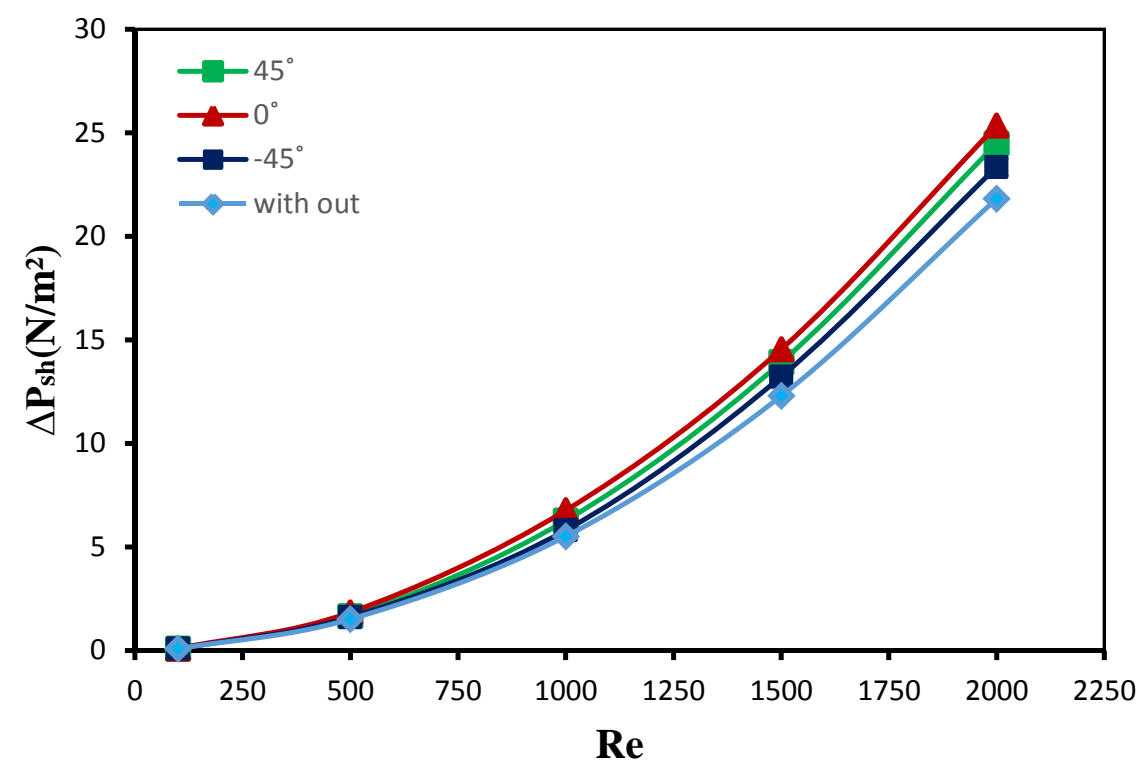

Fig. (6): Variation of shell side pressure drop with Reynolds number of shell for different angle baffle (degree) at $\mathrm{Re}_{\mathrm{t}}=600, \mathrm{Tci}=27^{\circ} \mathrm{C}$ and $\mathrm{Thi}=87^{\circ} \mathrm{C}, \mathrm{Nb}=5, \mathrm{Bh}=20 \mathrm{~mm}$. 


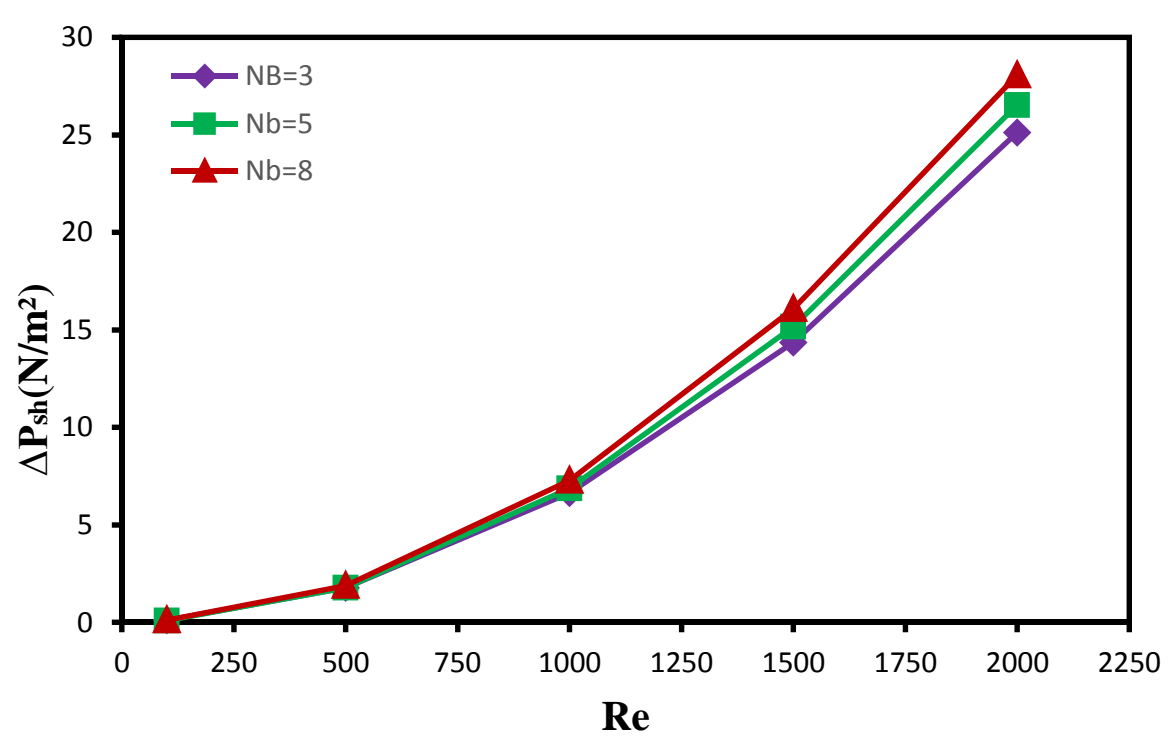

Fig. (7): Variation of shell side pressure drop with Reynolds number of shell for different number of baffle $(\mathrm{Nb})$ at $\operatorname{Re}_{\mathrm{t}}=600, \mathrm{Tci}=27^{\circ} \mathrm{C}$ and $\mathrm{Thi}=87^{\circ} \mathrm{C}, \mathrm{Bh}=30 \mathrm{~mm}$.

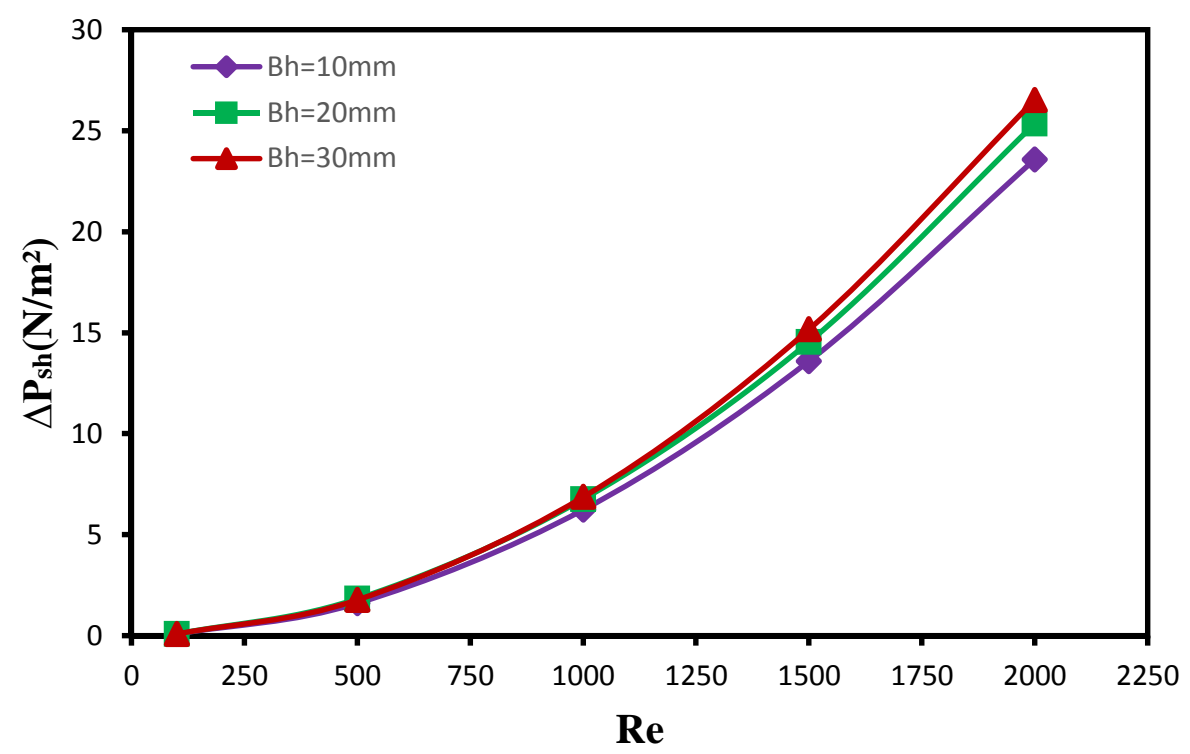

Fig. (8): Variation of shell side pressure drop with Reynolds number of shell for different baffle height (Bh) at $\mathrm{Re}_{\mathrm{t}}=600, \mathrm{Tci}=27^{\circ} \mathrm{C}$ and $\mathrm{Thi}=87^{\circ} \mathrm{C}, \mathrm{Nb}=5$. 


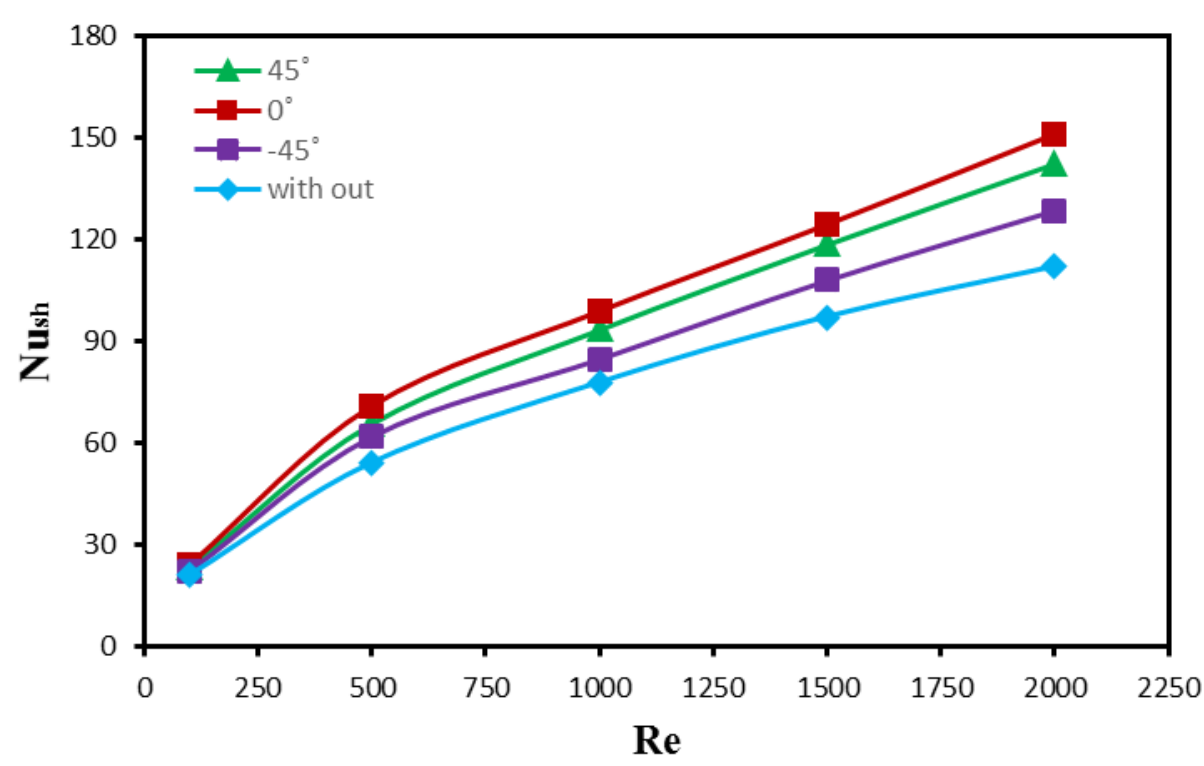

Fig. (9): Variation of average Nusselt number of shell side with Reynolds number for different angle baffle (degree) at $\mathrm{Re}_{\mathrm{t}}=600, \mathrm{Tci}=27^{\circ} \mathrm{C}$ and $\mathrm{Thi}=87^{\circ} \mathrm{C}, \mathrm{Nb}=5, \mathrm{Bh}=20 \mathrm{~mm}$.

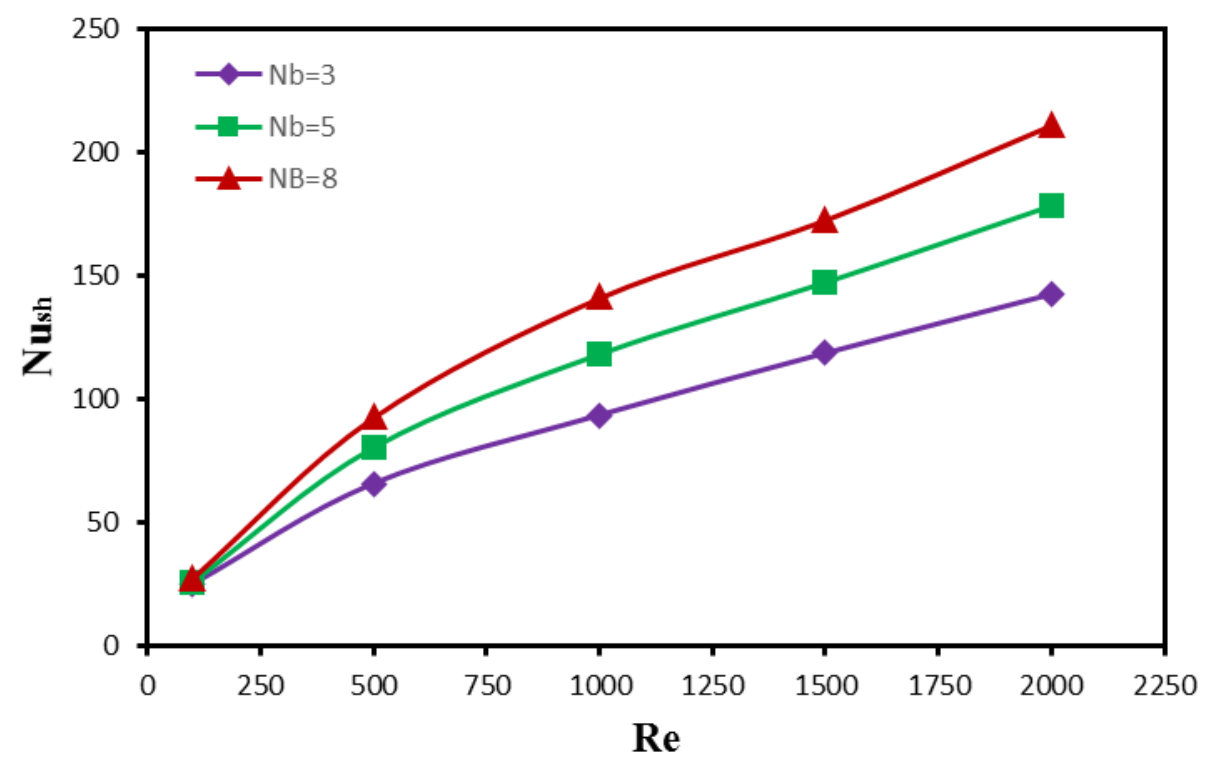

Fig. (10): Variation of average Nusselt number of shell side with Reynolds number for different number of baffle $(\mathrm{Nb})$ at $\mathrm{Re}_{\mathrm{t}}=600, \mathrm{Tci}=27^{\circ} \mathrm{C}$ and $\mathrm{Thi}=87^{\circ} \mathrm{C}, \mathrm{Bh}=30 \mathrm{~mm}$. 


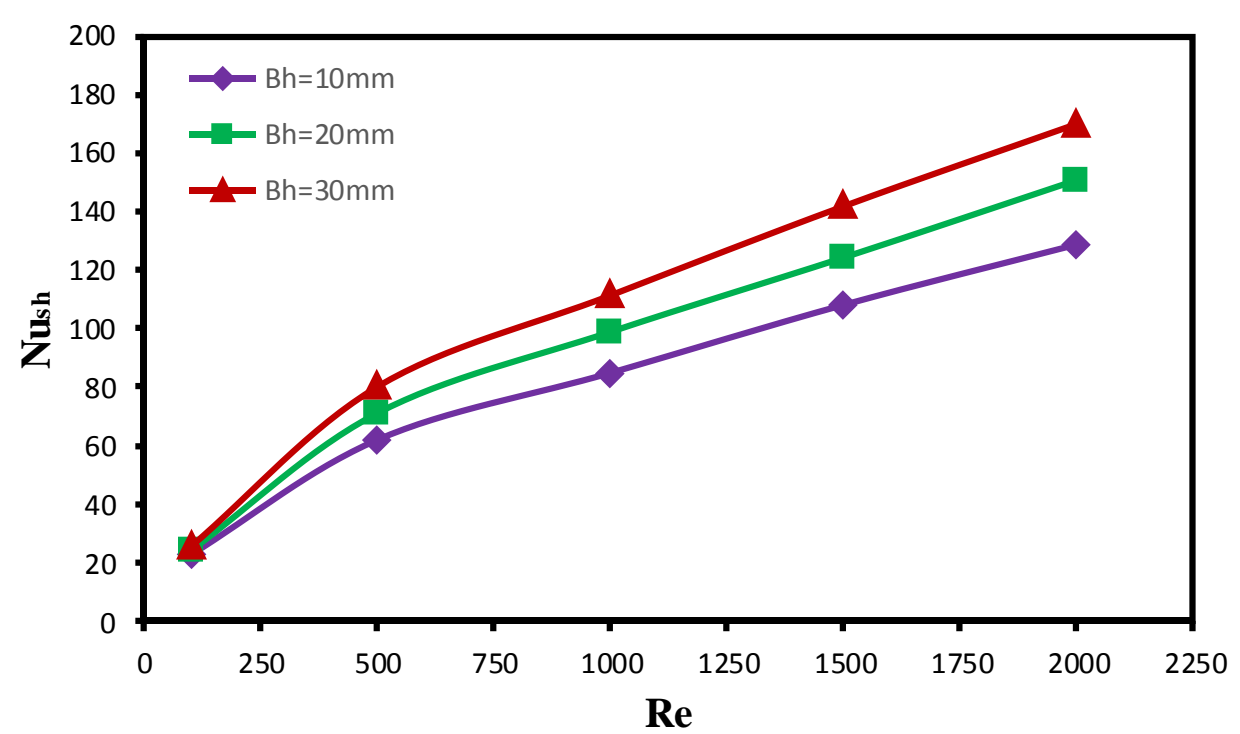

Fig. (11): Variation of average Nusselt number of shell side with Reynolds number for different baffle height (Bh) at $\mathrm{Re}_{\mathrm{t}}=600, \mathrm{Tci}=27^{\circ} \mathrm{C}$ and $\mathrm{Thi}=87^{\circ} \mathrm{C}, \mathrm{Nb}=5$.

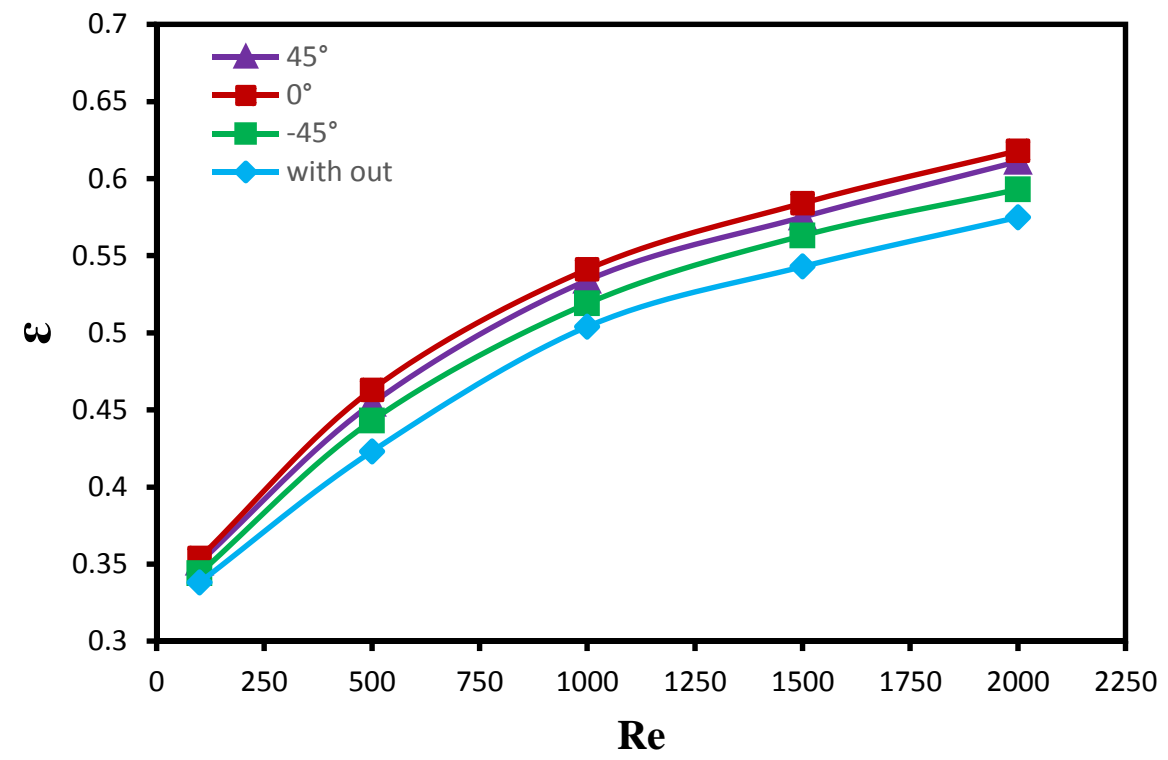

Fig.(12): Variation of heat exchanger effectiveness with shell Reynolds number for different angle baffle (degree) at $\mathrm{Re}_{\mathrm{t}}=600, \mathrm{Tci}=27^{\circ} \mathrm{C}$ and $\mathrm{Thi}=87^{\circ} \mathrm{C}, \mathrm{Nb}=5, \mathrm{Bh}=20 \mathrm{~mm}$. 


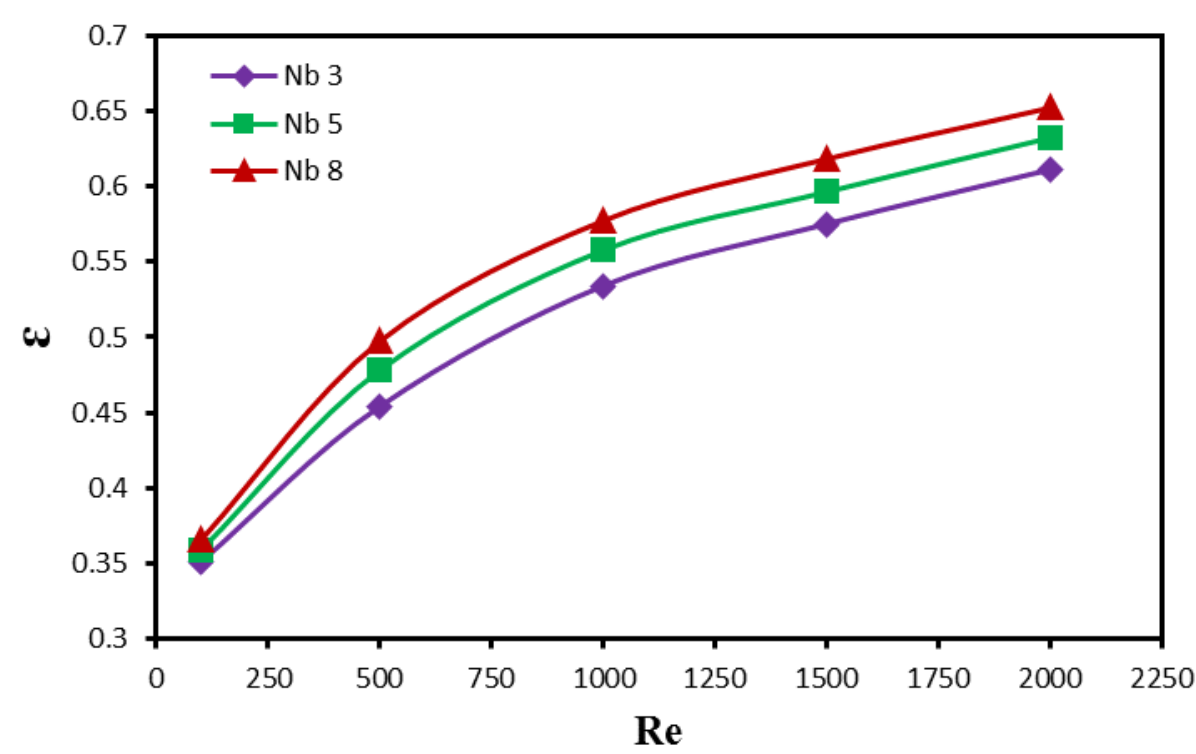

Fig. (13): Variation of heat exchanger effectiveness with shell Reynolds number for different number of baffle (Nb) at $\mathrm{Re}_{\mathrm{t}}=600, \mathrm{Tci}=27^{\circ} \mathrm{C}$ and $\mathrm{Thi}=87^{\circ} \mathrm{C}, \mathrm{Bh}=30 \mathrm{~mm}$

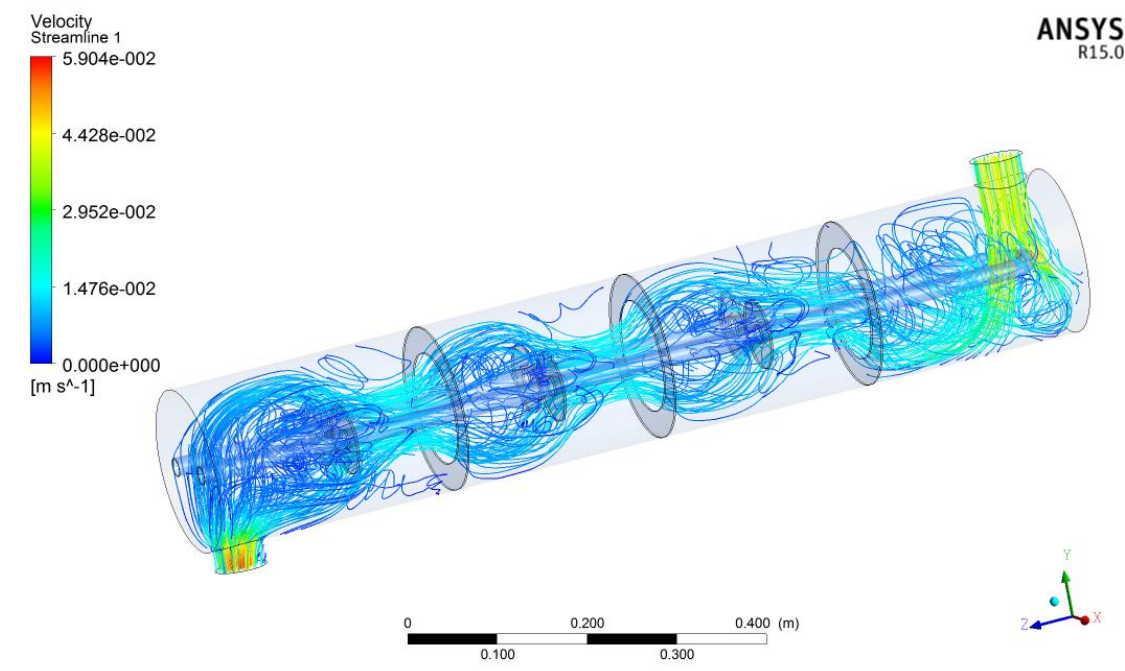

Fig.(14): Hot fluid velocity streamline distribution with vertical baffles.

\section{4-CONCLUSIONS}

Studied and analyzed the fluid flow and heat transfer in a heat exchanger type shell and tube was founded to be complex at cylindrical three dimensional (3D) and with baffles. CFD analysis plays an important rule for optimize shell and tube heat exchanger model. After the optimization procedure, baffles were effective parameters to enhanced heat transfer and effectiveness. At low flow rate there is a little effect of baffles on heat exchanger performance compare with high flow rate. 


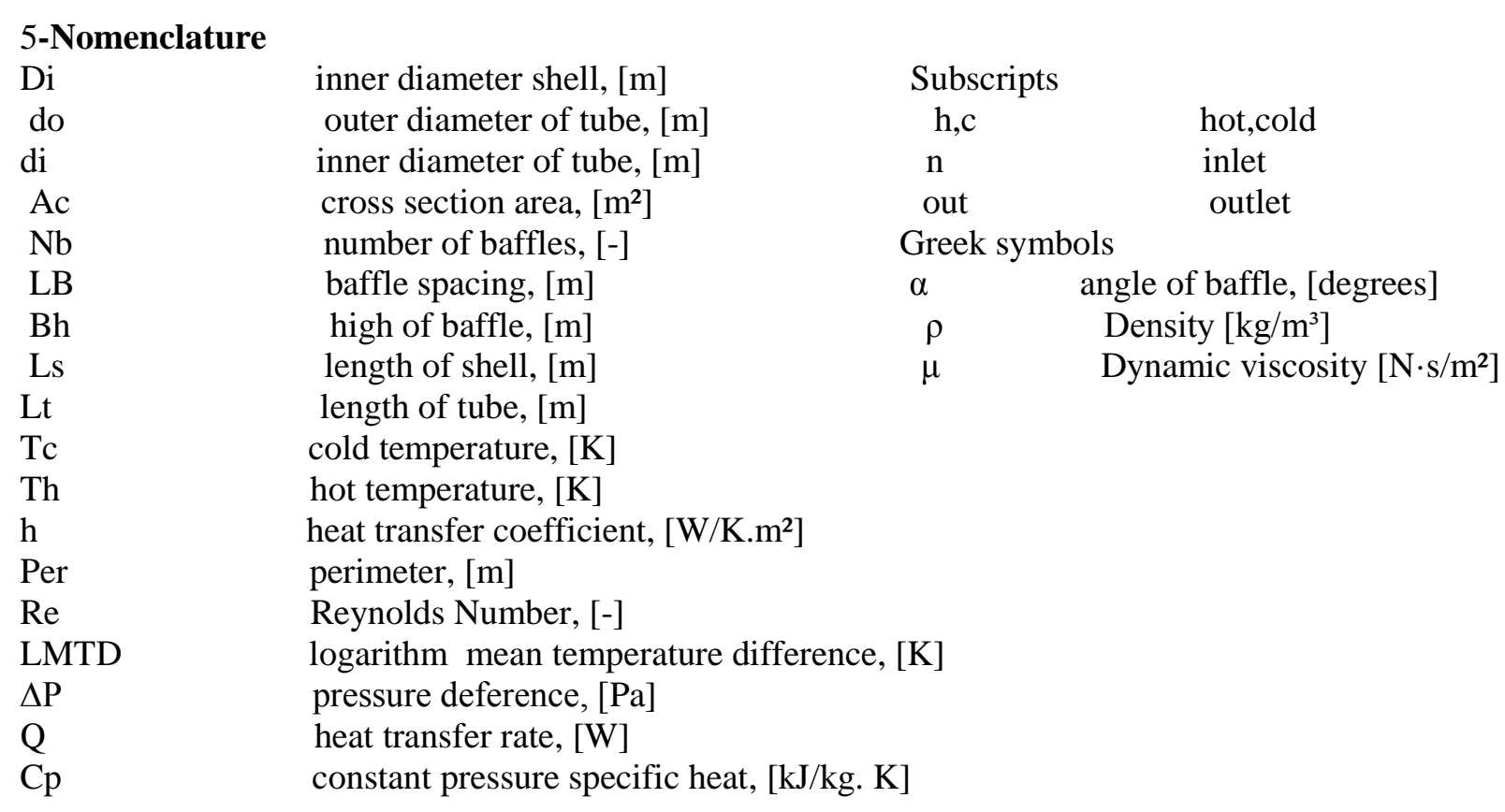

\section{REFERENCES}

[1] Mica V. Vukic1, Mladen A. Tomić , Predrag M. zivkovic1, Gradimir S. Ilic "Effect of segmental baffles on the shell-and-tube heat exchanger Effectiveness" Int. J. Heat Mass Tran. ,2014

[2] Mica Vukic, Goran Vuckovic, Predrag Zivkovic, Zarko Stevanovic, Mladen Tomi "3D Numerical simulations of the thermal processes in the shell and tube heat exchanger" Vol. 11, No2, 2013, pp. $169-180.2011$

[3] Mica Vukic, Dejan Mitrovic, Goran Vuckovic, Nenad Radojkovic, Gradimir Ilic, Zarko Stevanovic "Experimental study on thermal and flow processes in shell and tube heat exchangers" Vol. 1, No 10, , pp. 1377 - 1384. 2003

[4] Mica. Vukic, "Experimental and Numerical Investigations Thermal and Fluid Flow Processes in Shell and Tube Heat Exchangers" Ph.D. Thesis, University of Nis, Serbia. 2004

[5] Abdur Rahim and S.M. Saad Jameel, "Shell side numerical analysis of a shell and tube heat exchanger considering the effects of baffle inclination angle on fluid flow usingCFD", National Conference on Trends 2007
[6] P.S.P.Amirtharaj, S.Allaudinbasha, M.Janagan, R.Karthikeyan, S.Muthukumar, "Design and analysis of Shell and Tube Heat Exchanger with Inclined Baffles" International Journal of Scientific Development and Research"Vol.1. 2016

[7] Rajagapal Thundil, Karuppa Raj and Srikanth Ganne, "Shell side numerical analysis of a shell and tube heat exchanger considering the effects of baffle inclination angle on fluid flow", International journal of Thermal Science, Vol. No. 16, pp. 1165-1174, 2012.

[8] Yong- Gang Lei, Ya- Ling He, Rui Li and Ya- Fu Gao, "Effects of baffle inclination angle on flow and heat transfer of a heat exchanger with helical baffles", International journal of Chemical engineering and processing, Vol. No. 47, pp. 2336-2345, 2008

[9]Alok Vyas, Mr. Prashant Sharma, "An Experimental Analysis Study to Improve Performance of Tubular Heat Exchangers" Int. Journal of Engineering Research and Applications, Vol. 3,pp.1804-1809. 2013.

[10]White, F.M., Fluid mechanics. Boston, Mass.: McGraw-Hill. XIII, 866 s. 2003

[11] A. Bejan, A.D. Kraus, Heat Transfer Handbook, John Wiley, New Jersey, 2003. 